\title{
Sistem Informasi Geografis Pemetaan Rumah Tangga Miskin Pada Kecamatan Panekan Berbasis Web
}

\author{
Roy Arif Kurniawan Aminuddin \\ Fakultas Teknik, Universitas Merdeka Madiun, Jl. Serayu No. 79, Madiun, 63133 \\ E-mail: royarifkurniawan@gmail.com
}

\begin{abstract}
Mapping information system in poor households in panekan service were using the services of websites which digital maps. To make it easy for the central bureau of statistics central bureau of statistics (BPS) and the community panekan sub district in providing and to obtain any information to make a statement on information on households poor in panekan sub district, bi deputy governor muliaman $d$ this application is reasonable enough an integrated information system for. This information system to display location mapping poor households. With information system, everybody can see the mapping and information data on poor households the. In research this one is evolved a geographical information system the mapping of poor households on panekan sub district. System development in a build and fix, because they are considered quickly in the creation of a system. System that built can are expected to help bps and the community panekan. So that system that built must have the ability to form information mapping poor households accurately. For it, geographical information system mapping households poor in panekan sub distric have tested in a blackbox.
\end{abstract}

Keywords—: Web; Panekan Sub District; Poor Households; Information Geografis System; Build and fix.

\section{PENDAHULUAN}

Berdasarkan data dari Badan Pusat Statistik (BPS) Kecamatan Panekan Pada juni 2017, jumlah penduduk Kecamatan Panekan adalah 875 jiwa per $\mathrm{km}^{2}$. Angka ini terus meningkat sampai 880 jiwa per $\mathrm{km}^{2}$. Pertambahan jumlah penduduk yang sangat pesat secara tidak langsung berdampak pada jumlah rumah tangga miskin di Kecamatan Panekan. Dengan rancangan Sistem Informasi Geografis pemetaan rumah tangga miskin di Kecamatan Panekan Berbasis Web ini, diharapkan user dapat mengakses informasi rumah tangga miskin secara langsung melalui internet. Sistem ini dibuat berbasis web dan terhubung dengan jaringan internet. Dengan demikian datanya dapat dilihat dan ditampilkan dimana saja dan kapan pun dengan tepat waktu (BPS kecamatan Panekan, 2017).

Berdasarkan permasalahan di atas, maka akan dibangun sebuah sistem informasi geografis dalam memetakan kemiskinan di Kabupaten Cilacap Provinsi Jawa Tengah. Metodologi yang digunakan dalam membangun sistem ini adalah metode Waterfall. Tools yang digunakan dalam membangun sistem ini adalah google maps untuk membuat peta, PHP/MapScript sebagai bahasa pemrograman yang digunakan, kriteria nilai dari BPS dan $M y S Q L$ sebagai media penyimpanan data. Dengan dibangunnya suatu sistem informasi geografis pemetaan kemiskinan ini, masyarakat atau pemerintah akan lebih mengetahui perkembangan kemiskinan secara statistik, dan diharapkan seluruh lapisan masyarakat ikut serta dalam penanggulangan kemiskinan. Oleh karena itu, sistem informasi ini dapat dijadikan sebagai alat bantu yang mendukung penentuan penduduk miskin di Kabupaten Cilacap (Fuadi, 2011).

Sistem Informasi Geografis (SIG) merupakan suatu sistem informasi yang menekankan pada unsur informasi geografis yang meliputi data spasial dan atribut (basis data). Melalui SIG, pengguna dapat melakukan analisis terkait system yang diterapkan. Pemanfaatan SIG dalam penelitian ini yaitu bertujuan untuk membangun aplikasi peta berbasis Android dengan mengintegrasikan Google Maps API, dan web service. Aplikasi ini memuat informasi mengenasi sebaran rumah tangga miskin yang ada di Kabupaten Banyumas Terdapat beberapa Kecamatan di Kabupaten Banyumas yang memiliki jumlah rumah tangga miskin banyak, salah satunya Kecamatan Tambak. Dengan sistem ini pengguna dapat mengetahui titik - titik sebaran rumah tangga miskin tersebut. Selain itu pengguna juga akan di bantu dengan navigasi Google Maps apanila ingin mengunjungi rumah tangga miskin tersebut(Santoso, 2016).

Berdasarkan data dari Badan Pusat Statistik (BPS) Pekanbaru pada juni 2006, jumlah penduduk Pekanbaru adalah 779.899 jiwa. Angka ini meningkat dari tahun 2005 yaitu 754.467 jiwa. Pertambahan jumlah penduduk tersebut secara tidak langsung berdampak pada jumlah masyarakat miskin di Kotamadya Pekanbaru. Berdasarkan data dari Badan Pusat Statistik (BPS) Pekanbaru pada juni 2006, jumlah penduduk Pekanbaru adalah 779.899 jiwa. Angka ini meningkat dari tahun 2005 yaitu 754.467 jiwa. Pertambahan jumlah penduduk tersebut secara tidak langsung berdampak pada jumlah masyarakat miskin di Kotamadya Pekanbaru(Mardiana, 2011).

Kota Bukittinggi merupakan salah satu kota besar di Sumatera Barat dengan angka kemiskinan yang tinggi. Bukittinggi menempati urutan ke empat tertinggi Sumatera Barat dengan $4.96 \%$ dari jumlah penduduknya adalah penduduk miskin. Bukittinggi tercatat memiliki 2.694 rumah tangga miskin yang tersebar di 3 kecamatan denga 24 kelurahan. Kelurahan Puhun Tembok menempati urutan 3 terbanyak bagi rumah tangga miskin. 163 rumah tangga miskin yang ada tersebar di wilayah yang memiliki luas kurang lebih 70,9 km. lokasi yang tersebar dan informasi setiap rumah tangga miskin yang tidak akurat 
mengakibatkan program pengetasan kemiskinan menjadi tidak tepat sasaran. Oleh karena ini di bangunlah sistem informasi berdasarkan lokasi rumah tangga miskin Kelurahan Puhun Tembok yang berbasis web. Metode pengembangan perangkat lunak yang digunakan adalah metode waterfall. Aplikasi memiliki 7 kebutuhan fungsional, diantaranya pencarian rumah tangga miskin berdasarkan RW, bantuan yang diterima, pencarian rumah tangga miskin terdekat serta rute menuju rumah tangga miskin. Fungsional aplikasi diuji oleh 5 orang penguji. Hasil pengujian menunjukan 7 kebutuhan fungsional yang dirancang telah dipenuhi oleh aplikasi (Suryamen dkk, 2017).

Dari Penelitian yang pernah dilakukan dapat disimpulkan, sistem informasi geografis pemetaan rumah tangga miskin berbasis web adalah sistem informasi yang menyediakan dan menampilkan peta lokasi ruskin melalui web. Untuk membantu Badan Pisat Statistik serta masyarakat khususnya Kecamatan Panekan, maka Sistem Informasi Geografis Pemetaan Rumah Tangga Miskin pada Kecamatan Panekan perlu dibuat.

\section{METODOLOGI PENELITIAN}

Build and fix adalah sistem sangat mudah digunakan bagi pemula untuk pengembangan sistem informasi. Build and fix sangat cocok digunakan pada proyek berskala kecil, serta kelebihan build and fix lainya adalah tidak terlalu banyak perencanaan(Dhami, 2016).

Berikut adalah langkah-langkah menggunakan metode Build and Fix :

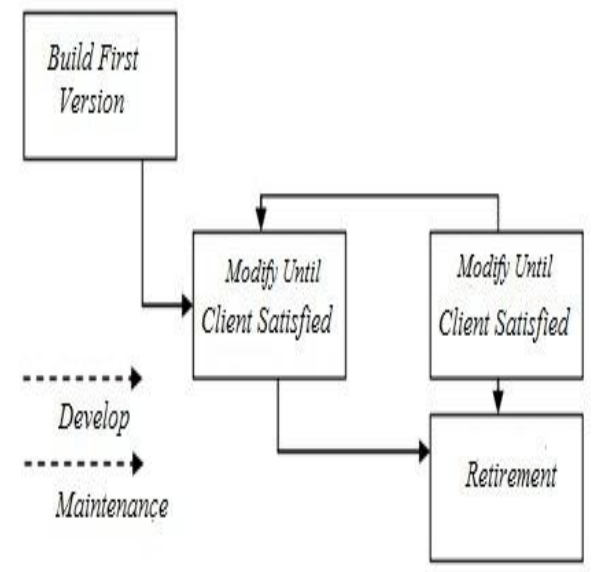

Gambar 1 Langkah-langkah Metode Build-and-Fix(Verma, 2014).

1. Build First Version

Membuat proyek dari awal sampai jadi, di tahapan awal ini development tidak memodifikasi proyek.

2. Modify Until Client Satisfied

Melakukan perbaikan sistem atau memodifikasi sistem secara terus menerus menurut permintaan kebutuhan pelanggan atau user sampai sempurna atau fix.

3. Retirement

Proyek dinyatakaan selesai dan proyek dapat dijalankan oleh pelanggan atau user.

Sedangkan untuk Metode untuk pengujian sistem, menggunakan metode Black Box. Di dalam Metode Black Box menggunakan butir uji, Butir yang diuji antara lain, butir uji user dan butir uji admin. Butir uji User terdiri dari, halaman utama (Home), halaman data ruskin, login admin, dan halaman about. Sedangkan untuk butir uji admin terdiri dari halaman login, halaman olah data ruskin, halaman tambah data ruskin, hapus data ruskin, cetak data ruskin, halaman olah data account, tambah user, dan logout. 


\section{III.HASIL DAN PEMBAHASAN}

Entity Relationship Diagram (ERD) yaitu menggambarkan hubungan antar objek, atribut dari masing-masing data.

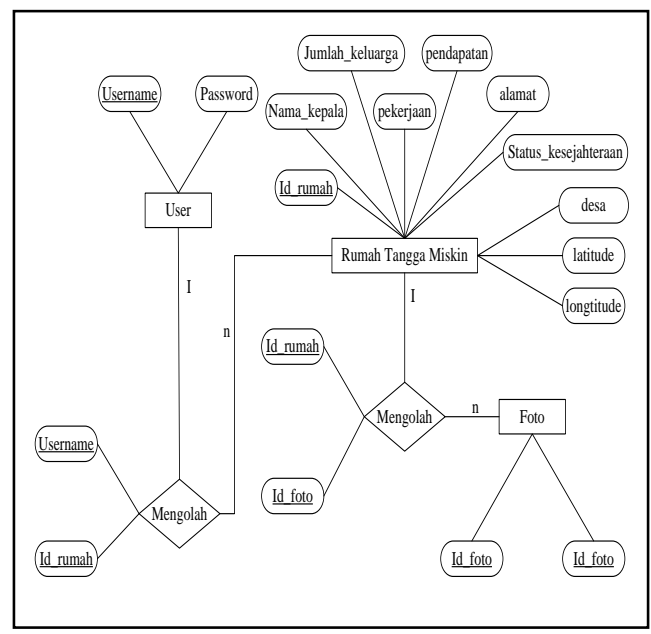

Gambar 2 ERD system

Berdasarkan diagram ERD pada Gambar 2 diatas, dapat dijelaskan sebagai berikut, Pada table login terdapat users, password dan nama. Pada tabel data rumah tangga miskin terdapat id_rumah, nama_kepala, jumlah_keluarga, pekerjaan, pendapatan, alamat, status_kesejahteraan, desa, latitude, dan longitude, dimana id_rumah sebagai primary key. Dan pada table foto terdapat id foto dan foto.

Dalam sistem informasi geografis pemetaan rumah tangga miskin pada kecamatan panekan. menggunakan perancangan model UML. Diagram UML yang akan digunakan dalam pengembangan sistem informasi bencana alam ini antara lain use case, Langkah awal perancangan pengembangan sistem informasi ini menggunakan use case diagram. Aktor yang tersedia adalah Admin dan Users. Berikut ini penggambaran use case:

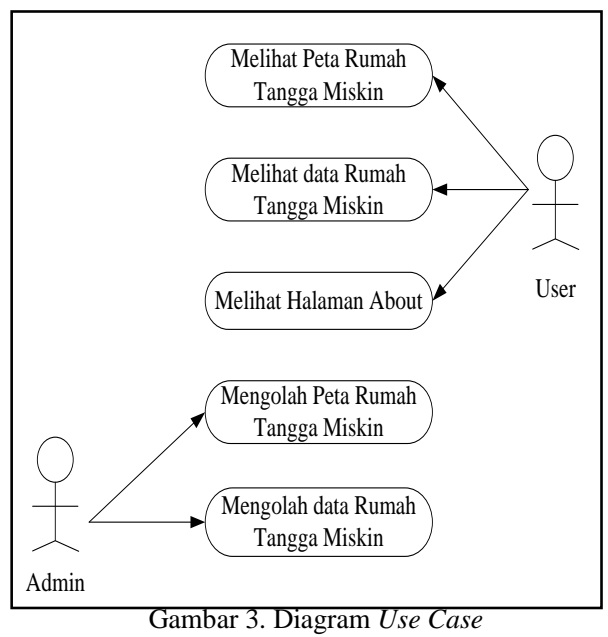

Berdasarkan Use case pada Gambar 3. Admin dan User harus terlebih dahulu membuka web sistem informasi rumah tangga miskin. Perbedaan admin dan user adalah user hanya dapat mengakses lokasi pemetaan rumah tangga miskin, sedangkan admin mempunyai hak sepenuhnya serta dapat memanipulasi data pada sistem informasi pemetaan rumah tangga miskin pada Kecamatan Panekan. Admin terlebih dahulu login untuk mengelola data pemetaan rumah tangga miskin. Didalam mengelola data pemetaan rumah tangga miskin admin dapat melalukan input tambah, hapus data. 


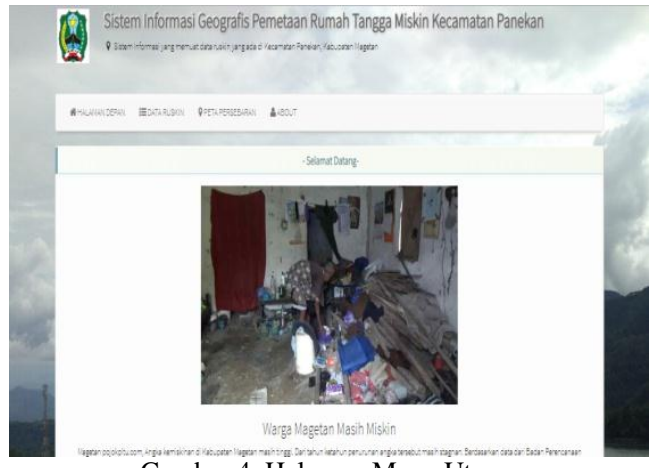

Gambar 4. Halaman Menu Utama

Halaman menu utama / home ini adalah halaman dimana pertama kali program dijalankan, halaman ini adalah tampilan untuk user, tanpa harus login.

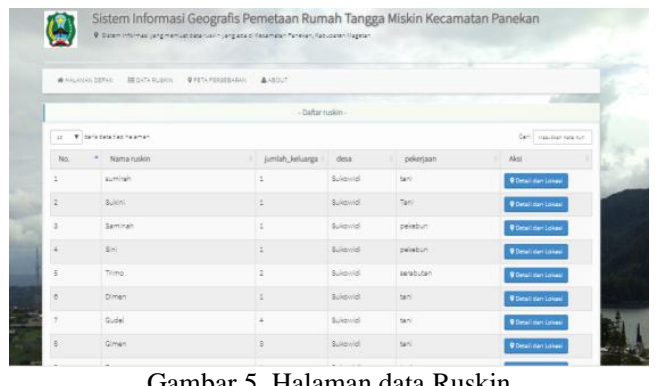

Seperti pada Gambar 5. Halaman Data Ruskin ini adalah halaman pertama yang dapat dilihat oleh user. Halaman Pada menu daftar data Ruskin pada Kecamatan Panekan.

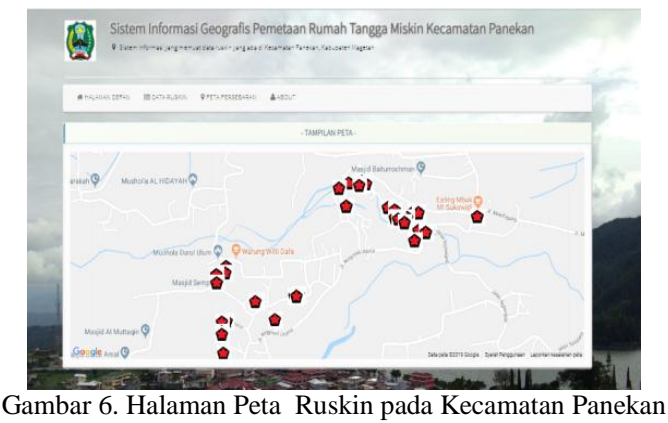

Berdasarkan Gambar 6, Halaman Peta Ruskin pada Kecamatan Panekan ini adalah halaman kedua yang dapat dilihat oleh user. Halaman.

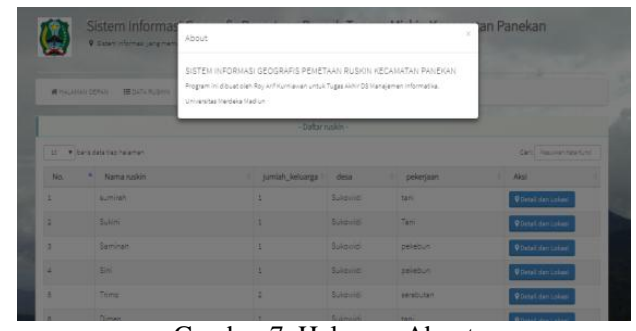

Gambar 7. Halaman About

Berdasarkan Gambar 7. Halaman About merupakan halaman dimana user dapat melihat profil singkat pembuat. 


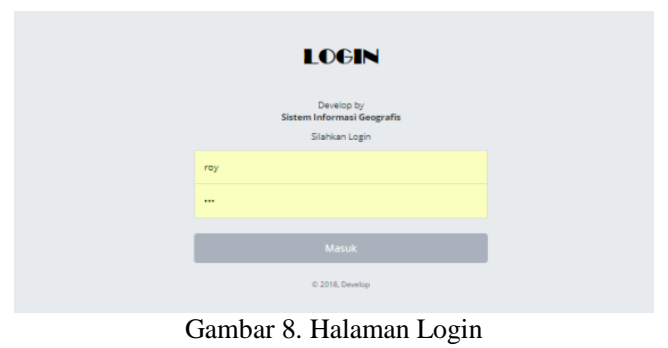

Berdasarkan Gambar 8. Halaman Login merupakan halaman dimana menjadi akses masuk menjadi Admin yang memiliki akses penuh terhadap website Sistem Informasi Geografis Pemetaan Rumah Tangga Miskin pada Kecamatan Panekan.

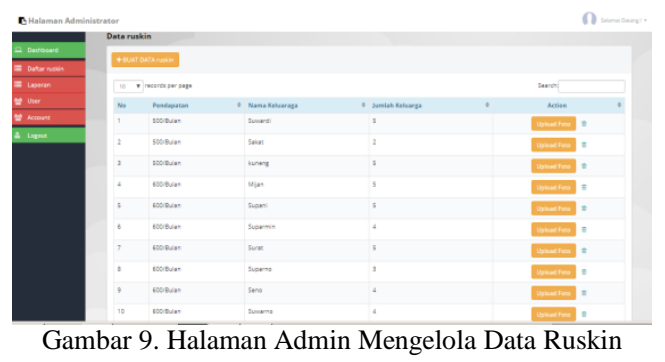

Berdasarkan Gambar 9. Halaman admin mengelola data Ruskin ini adalah menu halaman yang hanya bisa diakses oleh admin. Pada menu ini seorang admin bisa melakukan pengolahan aplikasi ini dengan melakukan penginputan, pencetakan data dan hapus data ruskin.

\begin{tabular}{|c|c|c|c|c|}
\hline \multirow{2}{*}{ Kelas Uji } & \multirow{2}{*}{ Butir UJI } & \multirow{2}{*}{$\begin{array}{c}\text { Tingkat } \\
\text { Pengujian }\end{array}$} & \multirow{2}{*}{$\begin{array}{c}\text { Jenis } \\
\text { Pengujian }\end{array}$} & Hasil \\
\hline & & & & Berhasil/Gagal \\
\hline \multirow{4}{*}{$\begin{array}{c}\text { Pengujian } \\
\text { Menu } \\
\text { User }\end{array}$} & $\begin{array}{l}\text { Halaman } \\
\text { Utama }\end{array}$ & $\begin{array}{c}\text { Pengujian } \\
\text { Unit }\end{array}$ & Blackbox & Berhasil \\
\hline & $\begin{array}{c}\text { Halaman } \\
\text { Data Ruskin }\end{array}$ & $\begin{array}{c}\text { Pengujian } \\
\text { Unit }\end{array}$ & Blackbox & Berhasil \\
\hline & $\begin{array}{c}\text { Halaman } \\
\text { Peta } \\
\text { persebaran } \\
\text { Ruskin }\end{array}$ & $\begin{array}{c}\text { Pengujian } \\
\text { Unit }\end{array}$ & Blackbox & Berhasil \\
\hline & $\begin{array}{l}\text { Halaman } \\
\text { About }\end{array}$ & $\begin{array}{c}\text { Pengujian } \\
\text { Unit }\end{array}$ & Blackbox & Berhasil \\
\hline
\end{tabular}

\begin{tabular}{|c|c|c|c|c|}
\hline \multirow[b]{2}{*}{ Kelas Uji } & \multirow[b]{2}{*}{ Butir טЛ } & \multirow[b]{2}{*}{$\begin{array}{l}\text { Tingkat } \\
\text { Pengujian }\end{array}$} & \multirow[b]{2}{*}{$\begin{array}{c}\text { Jenis } \\
\text { Pengujian }\end{array}$} & Hasil \\
\hline & & & & $\begin{array}{c}\text { Berhasil/Gag } \\
\text { al }\end{array}$ \\
\hline \multirow{9}{*}{$\begin{array}{l}\text { Pengujian } \\
\text { Menu admin }\end{array}$} & $\begin{array}{l}\text { Halaman } \\
\text { Login }\end{array}$ & Pengujian Unit & Blackbox & Berhasil \\
\hline & $\begin{array}{l}\text { Halaman Olah } \\
\text { Data Ruakin }\end{array}$ & Pengujian Unit & Blackbox & Berhasil \\
\hline & $\begin{array}{c}\text { Tambah Dats } \\
\text { Ruskin }\end{array}$ & Pengujian Unit & Blackbox & Berhasil \\
\hline & $\begin{array}{c}\text { Hapus Data } \\
\text { Ruskin }\end{array}$ & Pengujian Unit & Blackbox & Berhasil \\
\hline & $\begin{array}{l}\text { Cetal: Data } \\
\text { Ruskin }\end{array}$ & Pengujian Unit & Blackbox & Berhasil \\
\hline & $\begin{array}{c}\text { Halaman Olah } \\
\text { Data User }\end{array}$ & Pengujian Unit & Blackbox & Berhasil \\
\hline & $\begin{array}{c}\text { Tambah Dsta } \\
\text { User }\end{array}$ & Pengujian Unit & Blackbox & Berhasil \\
\hline & $\begin{array}{l}\text { Update Dasta } \\
\text { Account }\end{array}$ & Pengujian Unit & Blackbox & Berhasil \\
\hline & Logout & Pengujian Unit & Blackbox & Berhasil \\
\hline
\end{tabular}

Pada pengujian sistem didapatkan akurasi tingkat keberhasilan presentase akurat keberhasilan sistem sebesar 100\%. 


\section{IV.KESIMPULAN}

Pada penelitian ini, dapat diambil kesimpulan yaitu, telah dilakukan Perancangan dan pengembangan sistem informasi Geografis website ini berhasil dengan tingkat kemampuan sistem sebesar 100\% pada Butir Uji. Website yang di kembangkan ini dapat digunakan untuk membantu BPS Kecamatan Panekan dalam memberikan informasi geografis pemetaan rumah tangga miskin yang ada pada Kecamatan Panekan kepada masyarakat.

\section{DAFTAR PUSTAKA}

BPS kecamatan Panekan.,2017,'Panekan Dalam Angka 2017 Panekan Regenci In Figures 2017”. Badan Pusat Stastitik, Kecamatan Panekan.

Dhami, H,P,S., 2016, “Comparative Study and Analysis of Software Process Modelson Various Merits" International Journal of Advanced Research in Computer Science and Software Engineering OPJS University, Volume 6, Issue 9 , Rajasthan, India.

Fuadi, Ahmad Zaky. 2011. "Sistem Informasi Geografis Untuk Pemetaan Kemiskinan di Kabupaten Cilacap Berbasis Web (Studi Kasus di Badan Pusat Statistik Kab. Cilacap)”. [Skripsi Jurusan Teknik Informatika]. Malang: Universitas Islam Negeri Maulana Malik Ibrahim.

Mardiana, Rina., 2011. Sistem Informasi Penduduk Miskin Berbasis GIS. Studi Kasus : Kotamadya Pekanbaru.

Santoso, Teguh, jati., 2016. Sistem Informasi Geografis Pemetaan Rumah Tangga Miskin di Kabupaten Banyumas Berbasis Android.

Suryamen, H., Akbar, F., \& Fithriyyah, U. (2017). Pembangunan Sistem Informasi Sebaran Rumah Tangga Miskin Kelurahan Puhun Tembok Bukit tinggi. Jurnal Sisfo Vol. 06 No. 01 87-100.

Verma, Shikha.,2014, “Analysis of Strengths and Weakness of SDLC Models". International Journal of Advance Research in Computer Science and Management Studies, Volume 2, Issue 3, Delhi - India. 